\title{
Curación espontánea de una tistula estercolar post-operatoria
}

\section{HISTORIA CLINICA}

Publicamos la historia clínica de $\mathrm{T}$. R., paciente que en su sexto embarazo vióse frente a una serie de complicaciones, de las cuales salió triunfante. gracias a los imponderables de la me dicina, por no decir que merced al influjo divino que tendrála para mejores destinos.

Fue un caso curiosísimo de cierre espontáneo de una fístula estercolar consecutiva a una intervencián diri. gida a la extracción de un cuerpo extraño, dejado en la carvidad peritoneal. Como la tístula era lo suficientemente amplia, las curaciones dos veces al dia eran de necesidad imperiosa. Las materias fecales salían con tánta abundancia y facilidad que hasta as. caris lumbricoides, por ella fueron ex pulsados. Inesperadamente un día, cuando todo se aprestaba para una nueva intervención, que en este caso no podía ser otra que una amplia resección intestinal, por la fistula cesó el avenamiento, y poco a poco se obstruyó en su totalidad hasta quedar la paciente en excelentes condiciones, 10 días después de que su estructura animica se estremecía ante la perspectiva de una nueva operación acompañada de un cortejo angustloso pleno de desesperanza.
T. R., de 32 años; con antecedentes de tres partos (dos espontáneos y uno con cesárea, por presentación de hombro abandonada) y dos abortos que exigieron sendos raspados uterinos.

Menarquia a los 14 años. Ciclo $30 x$ 3. con dismenorrea. Serología negativa. Sin antecedentes patológicos generales dignos de mencionarse.

El 11 de diciembre de 1952, relata que su última menstruación se efectuó el 15 de octubre, pero que el 23 de noviembre tuvo hemorragia genital es casa e indolora y el 3 de diciembre arrojó una ccarnosidad., después de sentir dolores suprapúbicos y lumbares.

Agrega que desde entonces éstos, se han vuelto permanentes y que el 9 de diclembre dos veces experimen. tó la sensación de vértigo.

La paciente tiene un aspecto general muy bueno. Su tensión es de 11 por siete y en el momento del excrmen no tiene hemorragia genital. Sin em. bargo, al tacto, el cuello es largo, blando $y$ cerrado $y$ en anteposictón muy marcada; los fondos de saco son dolo rosos $y$ en el posterior se nota un, sl es, no es de crepitación; la moviliza. ctón cervical desplerta agudo dolor; la matriz no so puede circunscriblr con claridad. 
Se la pone en observacion y se le ordenan exámenes de laboratorio con el siguiente resultado:

\section{Serología: negativa.}

Sangre: Hematies, 4.300.000. Leucocitos: 9.400. Hemoglobina, 80\%. Polinucleares neutrófilos, $54 \%$. Eosinófilos, $4 \%$. Linfocitos, 38\%. Grandes mononucleares, $4 \%$. Sedimentación: a la me dia hora, $19 \mathrm{~m} . \mathrm{m}$. a la hora $38 \mathrm{~m} . \mathrm{m}$. Glucemia, 0,75\%. N. P. N., $27 \mathrm{mg} . \%$.

Orina: Albúmina y glucosa, nogativas. Sedimento, células ++ y leuco cilos, $t+$.

Como la paciente continuó quejándose de sus dolores, y el examen ginecológico no variaba, se decidió intervenir bajo el diagnóstico de embarazo ectópico. El 19 de diciembre se confirmó la presunción, pues al abrir la cavidad peritoneal se la encontró llena de coágulos, la trompa derecha estaba rota y rodeada de adherencias epiplóicas. Se hizo la correspondien te salpingectomía y como tratamiento post-operatorio, se ordenó dextrosa, pe. nicilina, hierro con vitamina C. y analgésicos.

Los dias consecutivos a la intervención en vez de traer la esperada me joría, tornan peor el estado de la enferma. La temperatura va ascendiendo hasta $39,5^{\circ} \mathrm{C}$, el vientre es duro y doloroso, el facies se torna pálido y cm. gustioso. Se sospecha que en la carvidad ha podido quedarse una compresá y se resuelve reoperar el 7 de ene ro. Eńtonces, se ve que las adherencias se han quintuplicado $y$, en efec- to, se extrae el cuerpo extraño $y$ se dejan drenes de caucho. La temperatura baja a $36,8^{\circ} \mathrm{C}$, mejora el estado general, mas, el 13 se observa que se ha formado una tremenda fístula estercolar que da salida a torrentes de materias fecales.

Se instituye un tratamiento con ácidos aminados, medio gramo de estreptomicina, cada 12 horas y vitami. nas. Se hacen curaciones dos veces al día y con desencanto se ve que la enferma se debilita paulatinamente $y$ que la fístula se agranda más.

Prosiguese el tratamiento para tonificar a la paciente y hacerle una re sección intestinal, a fin de hacer la curación de su fístula. Se escoge el 27 de enero para la intervención. Mas, el 26, súbitamente el apósito aparece seco y el día 27 se aprecia que ha cesado por completo la salida de materias estercóreas. Ante el unámime asombro por esta particular y excep cional evolución se espera el curso de los acontecimientos y 10 días después la cicatrización ha concluido satisfac. toriamente. Es de anotar que el mismo 26 de enero, día en que cesó el flujo por el conducto fistuloso, T. R., la protagonista de esta historia clínica, sintióse tan bien, que pedía se le diera de alta.

Es una evolución tan rara, que nos pareció interesante publicarla en la Revista de la Sociedad Colombiana de Obstetricia y Ginecología.

Ramón Francisco Sánchez 